\title{
Nancy Sue Palchik, PhD
}

\section{Assistant Professor, University of Michigan Medical School}

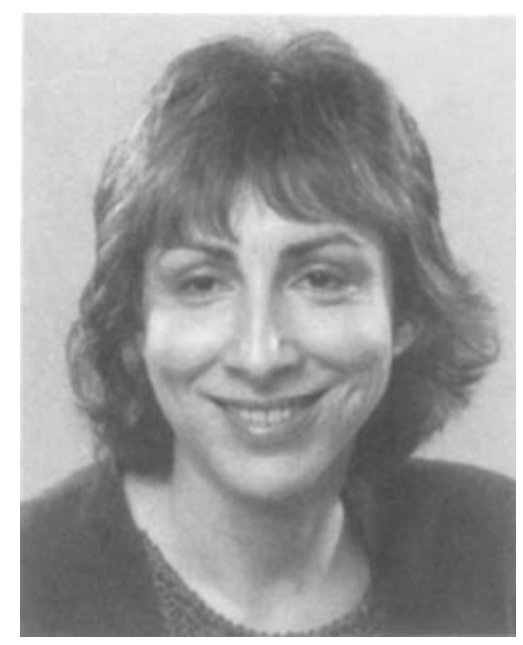

Nancy Sue Palchik

Nancy S. Palchik, PhD, 44, Assistant Professor in the Department of Postgraduate Medicine and Health Professions Education at the University of Michigan, died of cancer on May 4, 1991. Dr. Palchik received her PhD in Educational Psychology in 1984 from the University of Michigan and was appointed as an Instructor in the Medical School in the same year. She was promoted to Assistant Professor in 1987.

Dr. Palchik contributed significantly to the literature in the area of medical decision making and the use of Patient Management Problems in evaluating medical student performance. Her contributions have directed national attention to her research at the University of Michigan. She presented at numerous national meetings including the Arthritis Health Professions Association, the American College of
Rheumatology, the Association of American Medical Colleges, and the American Educational Research Assocation.

Dr. Palchik's administrative responsibilities have included Co-Director of the Educational Development and Evaluation Core of the Michigan Diabetes Research and Training Center, and Director of the Education Component of the Michigan Multipurpose Arthritis and Musculoskeletal Diseases Center. She was also the principal investigator and study director of the Osteoporosis Prevention Project of Michigan funded by the Michigan Department of Public Health. Goals of the study included determining the impact of exercise on the prevention of osteoporosis. This project has gained national attention due to significant research results linking exercise in early life to osteoporosis prevention.

Dr. Palchik served on doctoral thesis committees, taught medical school courses in medical interviewing, and served on several medical school, state, regional, and national committees.

Dr. Palchik is survived by her mother, Mollie, her daughter, Elizabeth, and her sister, Sally Regep.

Dr. Palchik was a respected researcher, enthusiastic collaborator and an individual whose personal characteristics inspired admiration and affection. Her work and scholarship have made a lasting contribution to the study of medical education. She will be missed by the members of her department, the Medical School faculty, and a wide circle of colleagues from around the country.

Wayne K. Davis, PhD Professor and Director Office of Educational Resources and Research University of Michigan School of Medicine

1991 by the Arthritis Health Professions Association. 